\title{
THE MASS PSYCHOLOGY OF CLASSROOM DISCOURSE
}

\author{
David I. Backer
}

\author{
Department of Professional and Secondary Education \\ West Chester University
}

\begin{abstract}
Aвstract. In a majority of cases observed in classrooms over the last several decades, what has gone by the name "discussion" is not discussion, but rather an interaction better known as recitation. If one sees this phenomenon as a problem, then an aspect of its resolution must be theoretical (as opposed to empirical or pedagogical): What series of conceptual terms might we adopt such that recitation does not pass for discussion? Such a theoretical response would have to address internal and external, or subjective and intersubjective, phenomena to describe what it means to participate in an interaction like discussion or recitation. Next the theory would have to explain the differences between interactions such as discussion and recitation in robust terms. Finally, these robust differences would have to prevent the "mistaking" of discussion for recitation, and vice versa. David Backer sets out to accomplish these three goals in the following essay. The theory he builds relies on a distinction between two psychological-affective states: dehiscence and melancholia. Backer argues that recitation forms a mass through melancholic introjection of a single object, while discussion forms a group that dehiscently introjects no particular object at all. The chief finding of this essay is that viewing discussion and recitation through the mass-psychological lens offers a new way to examine what kind of relations of influence and power form during classroom discourse and, specifically, the political significance of those discourses.
\end{abstract}

\section{INTRODUCTION}

In their extensive study of classroom discourse, Martin Nystrand and his colleagues conclude that while there is considerable "lip service" paid to discussion, what tends to occur during classroom discourse is something quite different: the traditional chalk-and-talk pattern known as recitation. Out of their 872 observations of teacher-student discourse in 200 classrooms in the United States, they found that less than 7 percent of 1,151 instructional episodes had one discussion. ${ }^{1}$ Earlier studies show how recitation has persisted as a form of classroom discourse over time and space as well. ${ }^{2}$ There are two related issues here. First, there is a lip service problem where discussion is announced but not enacted. In such cases, as the Nystrand study found, teachers say there will be discussion in their syllabi or course materials or at the start of class but then proceed to facilitate recitation. The second problem, known as such since at least 1969, is the persistence of recitation: recitation remains the default pattern of classroom discourse. These two problems

1. Martin Nystrand, Martin Wu, Adam Gamoran, Susie Zeiser, and Daniel Long, "Questions in Time: Investigating the Structure and Dynamics of Unfolding Classroom Discourse," CELA Research Report (Albany, NY: National Research Center on English Learning and Achievement, 2001), 36. Other studies in the last twenty years confirm this conclusion as well. See, for example, J. Nathan Swift, C. Thomas Gooding, and Patricia R. Swift, "Questions and Wait Time," in Questioning and Discussion: A Multidisciplinary Study, ed. James Dillon (Westport, CT: Greenwood Publishing Group, 1988).

2. James Hoetker and William P. Ahlbrand Jr., "The Persistence of the Recitation," American Educational Research Journal 6, no. 2 (1969): 145-167; Susan Stodolsky, Teresa Ferguson, and Karen Wimpelberg, "The Recitation Persists, but What Does It Look Like?," Journal of Curriculum Studies 13, no. 2 (1981): 121-130; and Courtney Cazden, Classroom Discourse: The Language of Teaching and Learning (Portsmouth, NH: Heinemann, 1988). 
raise many questions for researchers of classroom discourse. Why does recitation persist? Why does discussion get confused with recitation? How should we think about and practice discussion and recitation? What do the lip service to discussion and the persistence of recitation mean politically?

Educational theory is uniquely suited to address the last question. What is at stake politically when recitation is the predominant form of classroom discourse? What are the political consequences when a teacher says there will be discussion but proceeds to facilitate a recitation? In the tradition of educational theory, discussion promises liberal values and democracy since, among other things, it is described as a free exchange of ideas among equal, rational individuals deliberating in dialogue. ${ }^{3}$ Does recitation negatively influence this democratic promise? If a teacher leads a recitation instead of a discussion, is democracy compromised?

Existing responses to questions like these typically follow a pattern. First, they appeal to political theory. Second, they argue for a juxtaposition of classroom discourse practices with that political theory. Finally, they call for an increase in those classroom practices that amplify the presence, awareness, or instruction of the particular political values associated with the practices. One example of such a response is Walter Parker's argument that listening and discussion socialize students for democratic citizenship because these practices encourage political friendship. ${ }^{4}$ Parker draws from Aristotelian political theory in arguing that listening and discussion have a political significance in that theory, and calls for their further integration into classrooms. But this argument can say very little about the lip service to discussion problem. Appealing to political theory may not make sense of the confusion or help to prevent it. This essay claims that a different approach is required to address the politics of this lip service problem, one that appeals to a theory about what happens during discourse rather than arguing that a particular practice occasions political values.

Understanding classroom discourse in terms of group formation, or the distinct relations of influence and power that certain discourses create, is one such approach. What kinds of groups do recitation and discussion form, and how do

3. John Stuart Mill, John Stuart Mill: On Liberty, ed. Michael B. Mathias and Daniel Kolak (New York: Pearson, 2006); David Bridges, Education, Democracy, and Discussion (Windsor, UK: National Foundation for Educational Research, 1979); Nicholas Burbules, Dialogue in Teaching: Theory and Practice (New York: Teachers College Press, 1993); Walter C. Parker, Teaching Democracy: Unity and Diversity in Public Life (New York: Teachers College Press, 2003); Diana Hess, Controversy in the Classroom: The Democratic Power of Discussion (New York: Routledge, 2009); and Sophie Haroutunian-Gordon, Learning to Teach through Discussion: The Art of Turning the Soul (New Haven, CT: Yale University Press, 2009).

4. Walter C. Parker, "Listening to Strangers: Classroom Discussion in Democratic Education," Teachers College Record 112, no. 11 (2010): 2815-2832.

DAVID I. BACKER is Assistant Professor in the Department of Professional and Secondary Education at West Chester University, 700 South High St., West Chester, PA 19383; e-mail <dbacker@wcupa.edu>. His primary areas of scholarship are social foundations of education, critical pedagogy, and psychoanalysis. 
these group formations accord or conflict with political values? When addressing problems like lip service to discussion, it may be best to take a fresh look at why we characterize discussion as democratic and recitation as oppressive. ${ }^{5}$ This essay proposes that we first consider the processes of group formation that classroom discourses trigger and proceed to political characterization afterward. Though it is not typically used for this purpose, mass psychology can parse what kind of groups are formed by discussion versus recitation and thus take a fresh look at whether discussion is democratic or recitation is oppressive, antidemocratic, or otherwise. Mass psychology can therefore inform our thinking about the political significance of discussion and recitation, opening up possibilities for the theory and practice of classroom discourse. ${ }^{6}$

Consulting Sigmund Freud's foundational work Massenpsychologie und Ich-analyse (Mass Psychology and Analysis of the Ego), it becomes clear that recitation tends to form a mass through melancholic introjection of a single object. ${ }^{7}$ Extending Freud's analysis with Jacques Lacan and more contemporary mass psychologists such as Eugene Wolfenstein, we can see that discussion creates a different kind of group through dehiscent introjection of no particular object. In mass-psychological terms, a group discourse where all participants focus on a single person creates very different relations of influence than a discourse where participants focus on one another in heterogeneous patterns. ${ }^{8}$ This essay articulates a mass-psychological theory of these discourses in order to generate new

5. See Kris Gutierrez and Joanne Larson, "Language Borders: Recitation as Hegemonic Discourse," International Journal of Educational Reform 3, no. 1 (1994): 22-36. Paulo Freire's banking model of education is another clear example that I explore later in the essay. See Paulo Freire, Pedagogy of the Oppressed (1968; repr. New York: Continuum, 2007).

6. After World War I, Freud and the burgeoning field of psychoanalysis began addressing the ways that groups affect psychic life (thanks to Chris Higgins for this helpful characterization of mass psychology). For precedents on this usage of mass psychology, see Wilhelm Reich, The Mass Psychology of Fascism (New York: Orgone Institute Press, 1954); Eugene Victor Wolfenstein, Psychoanalytic-Marxism: Groundwork (New York: Guilford Press, 1993); Eugene Victor Wolfenstein, "Race, Racism and Racial Liberation," Western Political Quarterly 30, no. 1 (1977): 163-182; and Zvi Lothane, "Mass Psychology of the Led and the Leaders: With Some Thoughts on Current World Events," International Forum of Psychoanalysis 15, no. 3 (2006): 183-192. For an early application to education, see Siegfried Bernfeld, Sisyphus: Or, The Limits of Education (Berkeley: University of California Press, 1973). In general this essay participates in the tradition of psychoanalysis and education upheld and set out by Deborah Britzman and Peter Taubman. See Deborah P. Britzman, After-Education: Anna Freud, Melanie Klein, and Psychoanalytic Histories of Learning (Albany: State University of New York Press, 2012); and Peter Taubman, Disavowed Knowledge: Psychoanalysis, Education, and Teaching (New York: Routledge, 2012).

7. Sigmund Freud, Group Psychology and the Analysis of the Ego, trans. James Strachey (London: Hogarth Press, 1959). This work will be cited in the text as GP for all subsequent references. Note that in discussing this book in the text I use a more literal translation of the original German title to emphasize its focus on masses.

8. I address this focus on the form of discourse (rather than content) below, as well as the usage of "recitation" and "discussion" as formal labels. I do not intend to reduce or ignore the complexity of discourse by focusing only on the mass-psychological difference between one object of attention and many objects of attention. Rather, I intend to make a specific claim about this difference in order to inspire further thinking about discourse. 

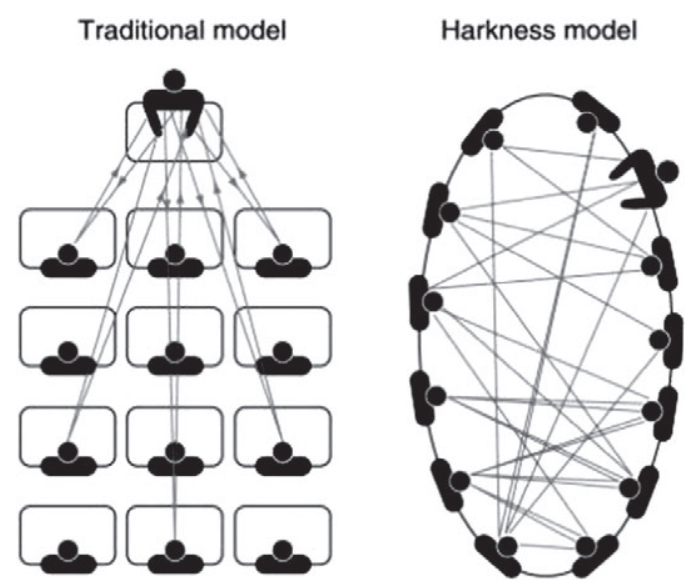

Fig. 1. Traditional model of classroom discourse versus a Harkness model: the left side depicts students attending to a single teacher, while the right side depicts students and teacher attending to multiple objects.

ways of thinking about the politics of classroom communication, two examples of which (Aristotle and Paulo Freire) are considered in the conclusion.

\section{Two Figures}

Let's begin by observing an interesting symmetry between two diagrams. Figure 1 is a picture used to distinguish Harkness teaching from "traditional" models of teaching. Figure 2 is Sigmund Freud's graphic representation of a mass, which is a group formation where a series of individuals attend to a single object. The symmetry exists between Freud's mass and the "traditional" side of the Harkness diagram on the left.

First, let's examine Figure 1. Harkness teaching, which originated at the elite New Hampshire boarding school Phillips Exeter Academy (although it is clearly an

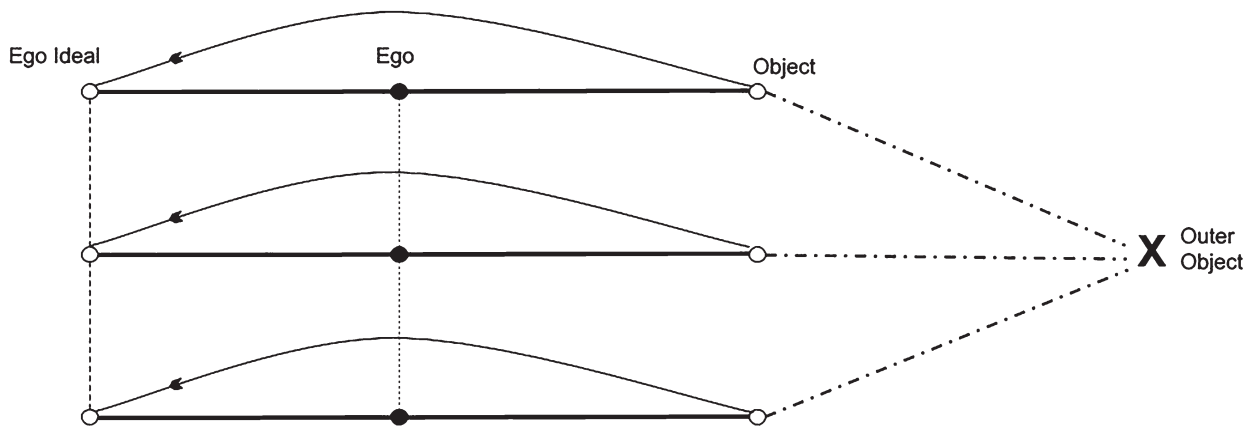

Fig. 2. Freud's depiction of a mass. ${ }^{9}$

9. This figure is from Freud, Group Psychology and the Analysis of the Ego, 91. 
outgrowth of the tradition of liberal arts seminars and dialogical, student-centered pedagogy), is a style of classroom facilitation where the teacher, among other important pedagogical moves, encourages students to speak to one another as much as (if not more than) to the teacher. ${ }^{10} \mathrm{My}$ reference to this pedagogical approach, and use of the Harkness diagram specifically, is meant only to provide a practical illustration of the argument to come. Other pedagogies, including many activist pedagogies, place a similar value on there not being a single object of attention. The more salient point for my purposes here is what James Dillon calls the "mix of moves" used during discourses like Harkness discussions. ${ }^{11}$ While he does not mention Harkness teaching, Dillon distinguishes recitation from discussion according to the manner and order in which teachers and students interact. $\mathrm{He}$ argues that discussion should have a mix of moves in which different participants address one another in different patterns. A recitation, for Dillon, has teachers asking more questions than students and following up student responses, with a high number of teacher-student exchanges. Courtney Cazden calls this pattern IRE, or teacher initiation, student response, teacher evaluation, repeat. ${ }^{12}$ During recitation, students attend to the teacher because the teacher is the one that initiates and follows up and initiates again. In a recitation, students' eyes are directed toward the teacher and their responses address the teacher's words. Recitations have other qualities as well, including short wait time, nonexploratory talk, low-level teacher and student questions, high number of back-and-forths, high percentage of teacher talk, and predetermined questions or materials under consideration. One thing that most accounts of recitation have in common - independent of subject matter, or content - is their description of the form of recitative discourse, which is consistently depicted as the sort of group formation shown on the left side of Figure 1. This is why I use a graphic from Harkness teaching as an example.

On the left side of Figure 1, the teacher, shown at the front of the room, is the single object of student attention. The diagram shows lines connecting each student to the teacher, depicting the way they address the teacher during discourse. They are seated in rows, the typical classroom formation for a recitation. The image names this assemblage the "traditional" model, and for good reason: as mentioned above, recitation has been shown to be the default educational pattern in classrooms across contexts. Although there are vastly different forms of discourse in schools, when thinking about what education looks like, from primary school to graduate school to professional situations, something like this single-object-at-the-front formation may come quickly to mind. This essay focuses on the form of classroom discourse as opposed to its content. Using mass

10. See David I. Backer, "Listening for Discussion: The Conference Method or Harkness Pedagogy," in Listening to Teach: Beyond Didactic Pedagogy, ed. Leonard J. Waks (Albany: State University of New York Press, 2015).

11. James T. Dillon, The Practice of Questioning (New York: Routledge, 1990), 16; and James T. Dillon, Using Discussion in Classrooms (Buckingham, UK: Open University Press, 1994).

12. Cazden, Classroom Discourse, chap. 4. 
psychology to examine the content of what students and teachers say would be a related (and fascinating) research project to pursue in the future; however, examining particular questions or topics or phrases uttered in classrooms is beyond the scope of this analysis. Thus the term "recitation" itself is contingent. While it will become important later when making political characterizations, whether we call the discourse-with-a-single-object-of-attention a recitation or discussion or conversation is beside the point at this stage of the argument. Still, for the sake of the forthcoming analysis, let "recitation" refer to the classroom discourse depicted on the left side of Figure 1 and "discussion" refer to what is depicted on the right side of Figure 1.

What are the mass psychologies of these discourses? Notice that Figure 2, aside from the labels naming each line and the different sorts of lines present, is symmetrical to the left side of Figure 1. If you turn this image 90 degrees counterclockwise, this becomes more apparent (see Figure 3).

There is a single outer object, marked as X. Beneath the $\mathrm{X}$, the graphic shows three vertical, solid black lines which represent distinct psyches attending to the

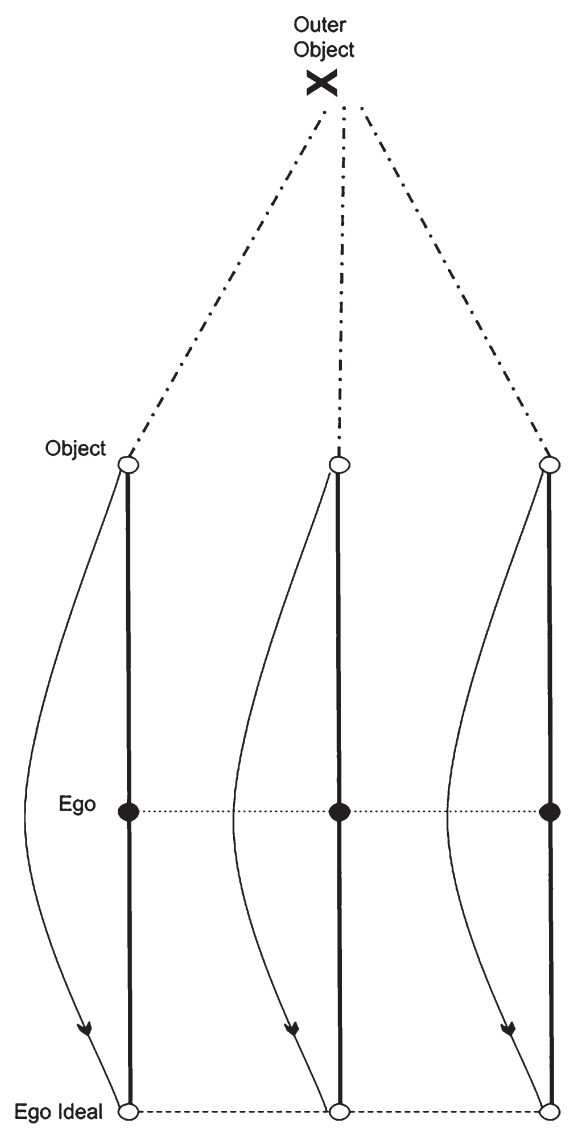

Fig. 3. Rotated view of Freud's mass illustration. 
outer object. It therefore could also depict a recitation with three students, or the first row in the class on the left side of Figure 1. Each solid line represents one individual and the dotted line emerging from the topmost end of the solid line, directed toward the outer object, represents that individual's attention. Whereas in other contexts this object X might be a painting, a pastor, or a dictator, with each alternative having its own distinct mass psychology, we are examining a set of students attending to a teacher, with whom they speak in a recitation. The other lines in the diagram correspond to terms and dynamics in Freud's theory of mass psychology, which he articulates in Massenpsychologie und Ich-analyse. This book examines why individuals behave differently in groups than they do when they are alone. He argues that existing explanations for these group formations are insufficient because they tend to rely on the notions of "suggestion" and "suggestibility," which refer to a state of vulnerability to influence, though none of them explain exactly what being suggestible means (GP, 33). Freud asks, what is going on when individuals get together and, upon forming groups, become suggestible? The analysis developed in response to this question has become a classic argument in group psychology and was therefore translated into English under the title Group Psychology and the Analysis of the Ego.

While the English title obscures this point, the use of Massenpsychologie in the original German title highlights that the book contains a theory of masses. This theory of masses draws from Freud's previous ideas about the dynamics of the ego ideal in the psyche through hypnosis, then goes further into the cathexes of object desire and identification, and concludes with the processes of introjection and melancholic ego-ideal replacement, each of which I explain below. In brief, mass formation entails the partially hypnotic introjection of a single object into a series of psyches that are attending to that object, melancholically replacing each individual's ego ideal with that object. This is the process of mass formation, which I argue below is the type of group that recitation forms (independently of its content). It will help to stay constantly rooted in the two figures from this section: classroom recitation and discussion, and Freud's diagram of a mass. Again, each solid black horizontal line in Figure 2 represents a single psyche. For the sake of this analysis, we will think of these lines as representing the students on the left side of Figure 1. Each of them attends to the teacher, who is the outer object $\mathrm{X}$ in Figure 2. Freud's theory of masses holds that when a series of psyches attends to the same outer object, the perceived object moves into the position of the psyches' ego ideals. My claim is that this same process happens during recitation. What does it mean for a perceived object - in this case, the teacher or recitation leader - to "move" into the position of students' ego ideals? Freud theorized that this movement is a combination of three processes, which I explain in detail below:

1. object desire cathexis with the outer object;

2. momentary lifting of the existing ego ideal through partial hypnosis; and

3. the melancholic introjection of the object. 


\section{CATHEXIS-Hypnosis-INTROJECTION}

Freud observes that when many psyches attend to a single object, the resulting relationship between each psyche and the object is like that between a hypnotist and a hypnotized person, where the latter "is in reality unconsciously concentrating his whole attention upon the hypnotist, and is getting into an attitude of rapport, of transference on him" $(G P, 97)$. In hypnosis these two people face one another, and there is a rapport between them. A transference occurs when an experience "awakens ... a portion of [a person's] archaic inheritance" (GP, 99), such as experiencing someone else in terms of one's Oedipal past. The hypnotized person focuses their attention on the hypnotist in such a way as to transfer certain kinds of meanings, expectations, and associations onto the hypnotist. As we will see, mass formation is a partially hypnotic transference between participant and leader: "hypnosis has a good claim to being described as a mass of two" $(G P, 100)$.

The transfer happens through a cathexis. James Strachey, translator of the 1959 English edition of Massenpsychologie, explains that "cathexis" derives from the Greek word meaning "I occupy," and "means the concentration or accumulation of mental energy in some particular channel" such that "the psyche's libidinal attention is directed towards, or rather infused into, the idea of some object in the outer world" $(G P, 55) .{ }^{13}$ A cathexis is a desirous attention with which a psyche settles on some object. The cathexis issues out toward the object in the world and ascribes significance to that object. In Freud's diagram, the dotted lines representing the perception of the outer object may also represent the psyches' cathexes reaching out to settle upon the outer object and ascribe it with meaning.

There are at least two kinds of cathexis relevant to mass formation: object desire and identification. The former is a direct desire for something, while the latter is the desire to take the place of something in relation to an object of desire. The classic Freudian example is a baby's cathexes for mother and father. One traditional iteration is that the baby desires mother and desires to take father's place, because mother's attention goes to father (though other iterations are likely). Parts of the psyche, such as the ego and the ego ideal, form over time through frustrated object desires and identifications; these complexes form as a result of sets of cathexes. While object desire is the simple libidinal attention toward a single thing, "identification endeavors to mold a person's own ego after the fashion of the one that has been taken as a 'model'" $(G P, 62)$. The famous Oedipal complex is the result of frustrated cathexes directed at people and things early in life, the stereotypical case being object desires for the mother figure and identifications with the father figure. Ordinarily, taboos and eventualities block and redirect these cathexes. "Mourning the loss" of people and things the psyche loves but cannot have, it does the next best thing: it sets up memorials to those people and things within itself, incorporating certain qualities and behaviors as an ideal. The psyche therefore behaves "melancholically," with mourning and melancholia acting as

13. The analogy Strachey uses is an electric charge. 
poetic metaphors for the psyche's everyday functioning and long-term formation. ${ }^{14}$ Freud writes about a young boy whose parents were concerned because he would sit under the dinner table and meow like a cat, for example. It came out in analysis that the boy had had a kitten and the kitten had died. Freud concludes that the loss of the kitten compelled the young boy to memorialize it through imitation. Having lost a loved object, a person may sometimes "transform themselves into" the loved object, "replacing the ego" with that object's qualities (GP, 65). The boy did just that, a response that Freud would characterize as a case of mourning through imitation.

But identification, in contrast to object desire, can have other consequences. Qualities and contents can be introjected and placed within the psyche as memorials of the lost object; this process, while mournful, is distinct from imitation. These memorials can cast a shadow over the ego, under which the psyche feels a kind of rage and sadness, a general melancholy. The falling shadow that forms as a result of melancholic introjection is the origin of the superego/ego ideal, a part of the psyche that is integral to Freud's account of mass formation since it enforces the embargoes and prohibitions to which the psyche holds itself accountable. Thus there is a "piece" of the psyche that is
a critical faculty within the ego, which even in normal times takes up a critical attitude towards the ego ... [and] develops in our ego and comes into conflict with it. We have called it the "ego ideal" ... [which] gradually gathers up from the influences of the environment the demands which the environment makes upon the ego and which the ego cannot always rise to.... [T] he [ego ideal's] origin [is] in the influence of superior powers, and above all of parents. $(G P, 69)$

Over time, the psyche issues out cathexes as object desires and identifications, some of which are frustrated. As the preceding passage describes, this ebb and flow of frustrated identifications forms a complex aspect of the psyche out of influences of the environment, incorporating qualities of people and things to which the ego aspires. These are "superior powers" it has loved and lost, and that it now memorializes. This is Freud's account of melancholic introjection, and it can be used to consider what happens during classroom discourse. In these terms, students enter classrooms having melancholically introjected many different kinds of qualities that compel them to be all kinds of things. When they sit down and face the teacher during a recitation, they enter into yet another rapport that draws forth a transference through cathexis in the teacher's direction. What happens next is similar to hypnosis.

In hypnotism, the hypnotized person cathects the hypnotist, who creates the conditions for the hypnotized to sleep. But this sleep is not the same as the dreaming sleep one experiences at night. What happens in this cathexis is a transference of the ego ideal onto the hypnotist. In other words, the hypnotist is

14. I set off the terms "mourning the loss" and "melancholically" with scare quotes to flag that I read them with Lacan as discursive metaphors for linguistic processes. See Lorenzo Chiesa, Subjectivity and Otherness: A Philosophical Reading of Lacan (Cambridge, MA: MIT Press, 2007), 64. 
experienced as the hypnotized psyche's ego ideal. Since the ego ideal is a part of the psyche that compels and commands the ego to be this or that, become this or that, the command to sleep puts the ego ideal to sleep, but not the entire psyche. The psyche experiences a removal of the ego ideal and deactivates the inhibitions it enforces once this rapport is established, such that the psyche feels released from those existing compulsions. ${ }^{15}$ Rather than holding one's own puppet strings, to use another metaphor, one briefly gives them over to someone else during hypnotism. Freud uses the German word Aufhebung to describe what happens in this "removal," which, in Totem and Taboo, is translated as a "lifting" of certain "embargoes on the whole world" (that is, the contents of the ego ideal). ${ }^{16}$ The hypnotist has become the ego ideal, since, in the transference, the psyche has cathected and now melancholically incorporates the hypnotist, who commands it to sleep. In the case of social and political formations like churches and armies, however, where there is a leader or a leading idea that many psyches cathect and introject, there is not a fully hypnotic relation between the outer object and the psyches. There is, rather, a "partial" hypnosis since the purpose of their gathering or communicating is not hypnosis itself but something else.

The consequent reaction of the psyche is not to fully relax or sleep but instead to "replace" existing ego-ideal contents with some official set of contents, whether it be church doctrine or army command. Thus the three-step process of cathexis, partial hypnosis, and introjection forms a mass when multiple psyches introject the same leader by replacing their ego ideals with that leader. Figure 2 depicts this movement of the leader into the ego-ideal position. The same process can be applied to understand recitation through the lens of mass psychology.

\section{The Mass Psychology of Recitation: Melancholia}

Depending on the students' comportment, development, and/or histories of trauma and fulfillment, the process can begin within the first few seconds of class. They sit, do certain things to settle into their seats, and look forward. The teacher begins speaking and the students focus their attention. The cathexes reach out, existing ego-ideal contents lift, and the psyches become partially hypnotized as they undergo a process of brief educational introjection, with which the teacher proceeds to work through the day's lesson. The teacher initiates through some comment or question, one student in the mass responds, the teacher says "interesting" or "good" or "okay" or "try again" or something like that, and then the teacher repeats the script. Recitation is under way. ${ }^{17}$

15. In the Massenpsychologie Freud is specifically concerned with "removal (Aufhebung) of those inhibitions (Triebhemmungen) upon [the mass participant's] instincts (Trieben)" (GP, 33).

16. Sigmund Freud, Totem and Taboo: Resemblances Between the Psychic Lives of Savages and Neurotics, trans. A. A. Brill (New York: Moffat, Yard, 1918), 46.

17. This is a simple fable of what happens in classrooms, but of course this is rarely how things go. It is merely meant to show that the language of cathexis, lifting, and introjection can help us think about the mass psychology of classroom discourse. 
This brief sketch is enough to articulate the mass psychology of recitation. Returning to Figure 2, the arching arrows that bring the perceived object to the ego ideal do so through the processes of identificatory cathexis of the outer object (teacher), substituting students' existing ego ideals, and introjecting the teacher by incorporating the teacher into their ego ideals through partial hypnosis. The students in a recitation form a mass when they move the teacher into the ego-ideal position via cathexis, hypnosis, and introjection (in other words, the application of Figure 2 to the left side of Figure 1). This mass is not the same sort of mass that an army forms around a general or a church forms around the image of Christ, but is instead a smaller kind of mass: the students form a mass around the teacher, who commands their attention and works with the openings of their psyches just enough for them to incorporate some lesson or other.

The next aspect of a mass (which is less important for our purposes) is that each member of the mass identifies in their egos with the other members. The dotted line between the egos represents this relation. Identification in the ego (as opposed to the identifying cathexis of the outer object that leads to the ego-ideal substitution) is an intensely ambivalent relation that can, at the same time, produce feelings of connection and repulsion, as in sibling relationships. When the ego ideal becomes uniform across psyches through introjection during partial hypnosis, members of the mass become a band of brothers, or "brothers in Christ" $(G P, 40)$, Freud says. They may feel an intense connection with each other and simultaneously feel aggressive toward each other.

In sum, then, the mass psychology of recitation has two relations: (1) a partially hypnotic relation of each student with the teacher, which compels them to melancholically introject the teacher's image into their ego ideals; and (2) an identificatory relation between students' egos. At this point we have enough language from mass psychology available to ask certain questions about the political characterization of recitation, specifically, whether a recitation accords with or contradicts certain political values like democracy. But before concluding with those questions, we will articulate the mass psychology of discussion.

\section{The Mass Psychology of Discussion: Dehiscence}

Returning to Figure 1, the right side of the diagram is a Harkness discussion. As I mentioned before, what is important about Harkness discussions is that they emphasize a mix of moves, an equal and varied sequence in students' focused attention during discourse. Rather than attending to one object, the students attend to many objects and voices in that moment, a dynamic that is illustrated by the cross-hatched lines around the circular table. What is the mass psychology of this mix of moves, as opposed to the homogeneous and unequal sequence in recitation? The students cathect, but not a single object. The right side of Figure 1 illustrates this type of situation in which the participants do not perceive a single uniform object. Their cathexes reach out as they would in any situation of focused attention, but the process of cathect-lift-introject pauses. They introject nothing 
in particular. $^{18}$ In discussion, the cathexes reach out to occupy a single object as they would in a mass, but the transference of the partial hypnosis remains unfinished at the second step: the "lifting" of existing compulsions occurs but there is nothing in particular to replace the ego-ideal contents. This is in contrast to the process that takes place in a mass: the psyche cathects, lifts the ego ideal, and introjects new contents as it focuses upon the singular object. In a recitation, this singular object is the teacher. The question, then, is what happens when existing ego-ideal contents lift in rapport, but there is no forthcoming replacement? In this lifting moment the ego ideal has deactivated, suspended, and it no longer compels the ego to be this or that, become this or that. ${ }^{19}$ I propose that Jacques Lacan's notion of dehiscence describes this situation.

In his early essay on the mirror stage, Lacan writes that there is a "primal Discord" at the heart of the human organism. ${ }^{20}$ In this "original tension," a psyche wants to know itself but cannot, taking as a compromise the closest thing it can get to a full picture of itself: its mirror image and the images of people and things around itself, incorporating these images into itself during the earliest cathexes. ${ }^{21}$ At this stage a baby will think that its reflection is itself in the mirror. Understanding its reflection as being itself, it will come to think of itself as being identical with that image (and other images, like parents or other people and things in its environment). The baby is like an eye trying to see itself. While the eye might be content with what it sees in the mirror or likenesses of the eye in books, a troublesome fact remains: the images and likeness of the eye are never the eye itself. The eye can never be included in the visual field, Wittgenstein observed. For Lacan, the same is true for the I: the self can never be included in the field of knowledge. The psyche can never know itself fully, yet it wants to, so it fills the resulting gap

18. There are several possibilities for this introjection of nothing in particular. The students might introject many voices and objects, no objects or voices, and/or a series of questions that may not be officially answered or endorsed by a leader. Exploration of each of these options must be reserved for further research.

19. Eugene Wolfenstein claims that in this situation "the group itself" is introjected (Psychoanalytic-Marxism, 271).

20. Jacques Lacan, "The Mirror Stage as Formative of the Function of the I as Revealed in Psychoanalytic Experience," in Ecrits, trans. Bruce Fink (New York: W. W. Norton, 2006), 78 (translator's capitalization). For a lucid account of Lacan's early theories of the stadu du miroir, see Elisabeth Roudinesco, "The Mirror Stage: An Obliterated Archive," in The Cambridge Companion to Lacan (Cambridge: Cambridge University Press, 2003), 25-34. For more on Lacan and classroom discourse, see Paul Moran and Mark Murphy, "Habermas, Pupil Voice, Rationalism, and Their Meeting with Lacan's Objet Petit A," Studies in Philosophy and Education 31, no. 2 (2012): 171-181; and Daniel K. Cho, Psychopedagogy (Basingstoke, UK: Palgrave Macmillan, 2009). For more on dehiscence in education, see David I. Backer and Tyson E. Lewis, "The Studious University: A Marxist-Psychoanalytic Groundwork," Cultural Politics 11, no. 3 (2015): 329-345; and David I. Backer, Elements of Discussion (Charlotte, NC: Information Age, 2015). The present analysis of dehiscence is limited due to constraints of space and theme, but it will be extended in a forthcoming paper on dehiscence in education through discussion.

21. Jacques Lacan, The Seminar of Jacques Lacan, Book II: The Ego in Freud's Theory and in the Technique of Psychoanalysis, 1954-1955, ed. Jacques-Alain Miller, trans. Sylvana Tomaselli (New York: W. W. Norton, 1991), 166. 
with images and the symbols of language. ${ }^{22}$ Lacan calls this "Discord," created by a desire to know the whole self that can never be fulfilled, a "dehiscence."

In anatomy, dehiscence refers to an opening in the body through which the internal organs are visible but do not come out. In this sense, the dehiscence is an opening in a body, otherwise whole, that reveals something which is typically hidden (the organs), blurring the lines between inside and outside, and thereby revealing the extent to which one's image of oneself is limited. A psyche in dehiscence is the same: a discordant gap opens, suspending the typical understanding of what the psyche is and is not. Dehiscence names that gap between what the psyche can know of itself and its unknowability. In later work Lacan would elaborate on dehiscence, characterizing it as a moment when the psyche loses a sense of what is and what is not, what is normal and strange, a kind of "torn" quality of desiring psyches. ${ }^{23}$ In other words, as a desiring thing, the known self is torn from the whole self, separated by the gap between what it can know about itself and its unknowability. Therefore, in the earlier essay, Lacan calls the dehiscence an "ecstatic limit of the "thou art that'": a basic, almost physiological separation between the self and its imaginary image, "an organic inadequacy." 24 Like alienation, a process that recurs throughout life, the dehiscence never goes away but rather returns again and again, since the psyche is caught up in a continual process of trying to answer the question about itself that it can never quite answer. ${ }^{25}$ In this way, dehiscence is an expression of one of Lacan's lasting contributions to the history of philosophy (which is to say, Freud's lasting contribution). Given the psyche's organic inadequacy, Descartes's idea that I think, therefore I am, is highly problematic. The "primary Discord" between the self's knowledge of itself and its unknown aspects yields the opposite conclusion for Lacan, who read Freud as ultimately troubling Descartes's maxim. Based on

22. Dmitri Nikulin expresses this relation between the self and the mirror image eloquently in Dmitri Nikulin, "The Man at the Mirror (Dialogue with Oneself)," Iris 3, no. 5 (2011): 61-79. For more on "gap" in Lacanian psychoanalysis, see the entry for "Gap" in Dylan Evans, An Introductory Dictionary of Lacanian Psychoanalysis (New York: Routledge, 2006), 72.

23. "The object is never for him definitively the final object.... But it thus appears in the guise of an object from which man is irremediably separated, and which shows him the very figure of his dehiscence within the world... It is in the nature of desire to be radically torn." Lacan, The Seminar of Jacques Lacan, Book $I I, 166$. The passage, and the notion of dehiscence in general, deserves more specific attention and will be the subject of a forthcoming essay on dehiscence in education through discussion.

24. Lacan, "The Mirror Stage as Formative of the Function of the I as Revealed in Psychoanalytic Experience," 79. I would like to thank the reviewers of this essay for the helpful phrasing of dehiscence I present in this sentence.

25. Bruce Fink uses the word "alienation" to describe this feature of the psyche, but I suggest that since, as Fink notes, "[this alienation] already appears in [Lacan's] article on the mirror stage" as the primal Discord mentioned in the previous passage, dehiscence should be conceived as the conditions for alienation. See Bruce Fink, The Lacanian Subject: Between Language and Jouissance (Princeton, NJ: Princeton University Press, 1995). 
the psyche's dehiscence, we might conclude that I think, therefore I am not. ${ }^{26}$ Dehiscence is the feature of the psyche that permits this conclusion.

The psyche in discussion, whose ego-ideal contents temporarily deactivate without forthcoming replacement, is a psyche in dehiscence. It is a moment that brings the psyche back to that primal Discord, its organic inadequacy. The mass psychology of discussion is thus dehiscent introjection, a collective dehiscence where nothing in particular is introjected after a cathexis has reached out and found no singular leader or leading idea to replace the lifted ego ideal. One can see this on the right side of Figure 1, where each participant has multiple lines emanating from them rather than one. When the psyche introjects no object in particular, the state of dehiscence initiated at the beginning of discourse continues as such, rather than incorporating new content into the ego ideal via introjection. Thus discussion is a group formed by dehiscent introjection of nothing in particular, as opposed to the melancholic introjection of a single object that occurs during recitation.

\section{CONCLUSION}

The initial concern of this essay was to characterize the political significance of discussion and recitation by articulating their respective mass psychologies. The purpose of doing so is to develop our understanding of the kind of groups each forms and thereby assess more accurately whether discussion is democratic and recitation oppressive or otherwise. To summarize: recitation forms a mass through melancholic introjection of one single object of attention while discussion forms a different kind of group through dehiscent introjection of no object in particular. Does a mass accord or conflict with democratic values? Does a dehiscent group? Let these questions comprise one substantive contribution. Readers interested in reevaluating the political character of classroom discourse now have access to a distinction that may prove useful: recitations form masses, but discussions, if they include a mix of moves, do not. At the very least, the problem of lip service to discussion articulated at the outset is less likely to occur when this theory is taken into consideration, since facilitators who are sensitive to the issue of mass formation might not behave in ways that promote mass formation if their interest is to avoid this outcome.

By way of conclusion, however, I will articulate two responses to the political characterization question posed here. To do so I draw from a reading of one aspect of Aristotle's theory of democracy in Politics. ${ }^{27}$ Part of Aristotle's idea of democracy

26. Derek Briton, "Learning the Subject of Desire," in Learning Desire: Perspectives on Pedagogy, Culture, and the Unsaid, ed. Sharon Todd (New York: Routledge, 2013), 62.

27. For contemporary perspectives on Aristotle's theory of democracy, particularly with respect to group formation, see Jill Frank, A Democracy of Distinction: Aristotle and the Work of Politics (Chicago: University of Chicago Press, 2005); Mathias Risse, "The Virtuous Group: Foundations for the 'Argument from the Wisdom of the Multitude'," Canadian Journal of Philosophy 31, no. 1 (2001): 53-84; Stephen G. Salkever, Finding the Mean: Theory and Practice in Aristotelian Political Philosophy (Princeton, NJ: Princeton University Press, 2014); and Bernard Yack, The Problems of a Political Animal: Community, Justice, and Conflict in Aristotelian Political Thought (Berkeley: University of California Press, 1993). 
requires that people in a democracy "rule in turns" so that different people achieve authoritative status. Although this exegesis is metaphorical at best given that the passages from Aristotle refer to elections and not classrooms, it is still interesting to see that Aristotle's idea of democracy requires that those who exercise power during democratic discourse must do so "in succession" and in such a way as to prevent any one of them from holding the leader position longer than others. Furthermore, Aristotle's language in the following passage illustrates dehiscence as well, since he contends that when rulers rule in turns, they are "no longer themselves":

Even among freemen and equals this is a principle that must be maintained, for they cannot all rule together, but must change ... in some order of succession. The result is that upon this plan they all govern; just as if shoemakers and carpenters were to exchange their occupations, and the same persons did not always continue shoemakers and carpenters. And since it is better that this should be so in politics as well ... that equals should in turn retire from office and should ... be treated alike. Thus the one party rules and the others are ruled in turn, as if they were no longer the same persons. ${ }^{28}$

The purpose for including this passage is to illustrate the usefulness of a mass-psychological approach to classroom discourse when characterizing the politics of pedagogy. According to the metaphorical reading I propose, when Aristotle writes "rule" above, we may read it as "speak," and "govern" as "discuss." "Equals" and "freemen" refer to teachers and students, an idea with which many might take issue both pedagogically and politically. ${ }^{29}$ On this reading, teachers and students, when they speak in turns, discuss together as if they are no longer the same persons, both in terms of their roles as the-one-who-speaks and as facilitator. A classroom where speakers speak in turns, therefore, is a democratic classroom. In this case, a democratic classroom discourse requires teachers and students to "exchange occupations" as they pass the office of speaker to one another in a mixture of ways. Just as, according to Aristotle, one person does not rule in a democracy, one person does not act as the single focus during discourse in a democratic discussion.

This reading of Aristotle resonates with the mass psychology of classroom discourse articulated here. A discussion with a mixture of moves satisfies this democratic requirement, whereas a recitation with one person at the center of attention would be monarchic. While a teacher might have democratic intentions, the classroom discourse that teacher facilitates might be monarchic. A monarchy in the classroom is not necessarily oppressive, but it certainly is not democratic. Is monarchy best in classroom discourse? Some might think that democracy in civil society is best achieved through monarchy in the classroom, but viewed through the lens of the theory spelled out here, the mass does not meet Aristotle's turn-taking stipulation for democracy. I would argue that a monarchic classroom

28. Aristotle, Politics, $1261 \mathrm{~b}$. Aristotle reiterates the same claim at $1279 \mathrm{a}$ : "And so in politics: when the state is framed upon the principle of equality and likeness, the citizens think they ought to hold office by turns" (emphasis added).

29. Pedagogically, it is controversial whether teachers are students' equals. Politically, Aristotle's theory of democracy infamously comes with a notion of natural slavery. 
discourse may undo, dilute, and/or complicate other democratic features of a teacher's pedagogy. Furthermore, given that dehiscence is a kind of "ego-ideal-less" state, Aristotle's metaphor of exchanging occupations such that one no longer feels like oneself is apt. In a mix of moves during discourse, according to the mass psychology of discussion articulated here, participants may sense a deactivation of that part of themselves which compels them to think they are thus and so, as if they were no longer the same persons (read: no longer students). Dehiscence, from this perspective, is a democratic mass-psychological phenomenon; melancholia, which is encouraged by recitation, does not have the same democratic quality since students will most likely continue feeling like students during a recitation.

This Aristotelian case is just one possible application of a mass-psychological approach to the political characterization of classroom discourse. Another is an augmentation of certain aspects of Paulo Freire's theory of dialogue, hinted at in a previous section. A pedagogy of oppression spreads narration sickness in the classroom by following the banking education model, in which teachers fill the empty minds of students as if they are making deposits into a bank. ${ }^{30}$ Mass formation is a theorization of banking education, where melancholic introjection replaces existing ego ideals with the object of the teacher. Narration sickness is a sickness because it is partially hypnotic; the oppression is oppressive because it is repressive, replacing students' ego ideals through introjection. In dialogue, on the other hand, teacher and students become teachers-students and students-teachers for Freire. This blending of roles is another dehiscent situation, like Aristotle's exchange of occupations. Collective dehiscence in the classroom is the mass psychology of dialogue. If this is the case, then we can claim that there is no dialogue without discussion. Without a mix of moves, a monarchical classroom discourse will compel students to introject a single object in place of their ego ideals. Given the mass psychology of classroom discourse, a dialogical teacher must facilitate a discussion in order to remain dialogical.

These are two kinds of conclusions we might draw from the mass psychology of classroom discourse articulated here. The chief finding of this essay is the mass-psychological lens itself: group psychoanalysis of discussion and recitation is a fresh way to think about what is happening during those patterns of communication. Whereas recitation forms a mass through melancholic introjection of a single object, discussion forms a group that dehiscently introjects no particular object at all. This can help to distinguish what kind of relations of influence and power form during classroom discourse, as in the Aristotelian proposal above, and offers a new way to look at how to think through the political significance of those discourses. Finally, the essay has accomplished one other thing. I began by citing the trend noted by Nystrand et al. and others that recitations are taking place where discussions are meant to occur - that is, that there is substantial "lip service" to discussion. I hope this essay has communicated how different these discourses are and what is at stake in confusing one for the other.

30. See Freire, Pedagogy of the Oppressed. 